- The study has confirmed that persons in areas of low socio-economic status are more likely to report orofacial pain.

- Socio-economic status per se does not influence the onset of symptoms but is only a marker for a set of environmental and individual factors which may influence onset.

- This study in examining some specific mechanical, psychological and behavioural factors has demonstrated that they cannot account for the excess symptoms amongst those living in areas of low socio-economic status.

\title{
Why is pain more common amongst people living in areas of low socio-economic status? A population-based cross-sectional study
}

\author{
V. R. Aggarwal, ${ }^{1}$ T. V. Macfarlane ${ }^{2}$ and G. J. Macfarlane ${ }^{3}$
}

\begin{abstract}
Study objective To confirm a relationship between self-reported oro-facial pain and deprivation using an area-based measure of deprivation, and to investigate possible mechanisms of the association.
\end{abstract}

Design A cross sectional population based survey.

Setting General medical practice in South-East Cheshire (Borough of Congleton, North West England).

Participants Two thousand, five hundred and four people aged 1865 years living in the community.

Methods A postal questionnaire was sent which asked about pain in the oro-facial region. Information on factors which may 'explain' any relationship between pain and social class was collected: psychological distress, maladaptive responses to illness, sleep problems and local mechanical factors such as teeth grinding and facial trauma. Participants were allocated a Townsend index deprivation score on the basis of their postcode.

Main results The study achieved an adjusted participation rate of $74 \%(N=2,504)$ and the overall prevalence of oro-facial pain was $26 \%$. Statistical analysis revealed that people in the most deprived areas were more likely to report oro-facial pain compared with the most affluent ones [OR 1.50 (95\% confidence interval 1.09, 2.07)]. This relationship remained after adjusting for all potential confounding factors.

Conclusion While the relationship between oro-facial pain and deprivation exists, the mechanisms of such relationships are not clear. Local mechanical factors, trauma or psychological distress did not explain it. The factors linking pain with social deprivation remain to be elucidated.

\section{INTRODUCTION}

The link between deprivation and health has been demonstrated in a number of studies, with populations living in deprived areas exhibiting levels of mortality, particularly below the age of 65, which vastly exceed those in affluent areas. ${ }^{1,2}$

The relationship between pain and deprivation has also been highlighted in population surveys. Andersson et al. ${ }^{3}$ showed that the prevalence of chronic pain varied with socio-economic levels and was highest among blue-collar workers of all ages. Whitecollar workers reported chronic pain less often than other groups. Papageorgiou et al. ${ }^{4}$ found a modest relationship between reported low back pain and social class in a cross sectional survey (relative risk 1.2 [95\% confidence interval 1.0,1.5]). They also showed, in a one year follow-up study, that people from lower social classes were more likely to consult with a new occurrence of low back pain. Locker ${ }^{5}$ showed that subjects with low educational or economic status were more likely to report one or more oro-facial pain symptoms. More recently, Vargas et $a l .{ }^{6}$ found that for persons aged $20-64$ years of age, those with lower socio-economic status characteristics were more likely to report tooth pain, and endure their pain without the benefit of dental care, than are their counterparts with higher socio-economic status characteristics. However, these studies did not establish why people of lower social class are more likely to have pain.

Therefore, using the syndrome of oro-facial pain, we wished to firstly confirm that pain was more common amongst those living in areas of lower social status. Secondly we wished to determine why pain was more common. We hypothesised that one or more of the following could explain the increased likelihood of pain: higher levels of psychological distress, poorer oral health, greater likelihood of injury and/or maladaptive response to illness.

\section{METHODS}

\section{Participants}

Study participants were 2,504 people aged 18-65 years registered with a general medical practice in South-East Cheshire (Borough of Congleton, North West England) who participated in a crosssectional population survey of oro-facial pain. The adjusted participation rate was 74\%. Participants completed a self-complete postal questionnaire for the survey, which commenced in 0cto- 
ber 1997. Data collection was closed at the end of July 1998. Ethical approval for the survey was granted by the Macclesfield Research Ethics Committee, East Cheshire NHS Trust.

\section{Outcome measure}

Oro-facial pain was defined as present if the respondent had experienced at least one type of pain during the past month: in the jaw joint/s; in the area just in front of the ear/s; in or around the eyes; when opening the mouth wide; in the jaw joint when chewing food and in and around the temples. Oro-facial pain was also recorded if there had been tenderness of muscles at the side of the face, prolonged burning sensation in the tongue or other parts of the mouth and shooting pains in the face or cheeks.

\section{Measure of deprivation}

Deprivation was measured by the Townsend index, an area-based score derived from postcode sectors or wards. ${ }^{7}$ It has been used in previous studies of a variety of health disorders. ${ }^{2,8-10}$

All postcodes of the participants were successfully matched to corresponding enumeration districts, which were derived from the 1991 census data. ${ }^{11}$ Each enumeration district has a corresponding Townsend index score. The Townsend index ${ }^{7}$ is a composite score based on four key variables: percentage of residents' unemployed, overcrowded households, households without a car and non-home ownership.

The Townsend index score for England and Wales has values ranging from -7.55 to 11.80 . A positive Townsend score indicates material deprivation with a higher score representing a higher degree of deprivation. A negative Townsend score represents comparative affluence. For the purpose of data analysis, we divided the Townsend score for the whole of England and Wales into quintiles.

\section{Other health and status measures}

The following information on factors which could 'explain' any relationship was also collected by the postal questionnaire:

- Demographic factors: age, gender.

- Oral health factors: attendance for dental check ups at least once a year, teeth grinding, number of missing teeth.

- Facial injury: history of facial trauma.

- Psychological distress: measured using a twelve-item general health questionnaire (GHQ). ${ }^{12}$ Each item was scored as 0 or 1 giving a score between 0 and 12 . High scores indicated high levels of psychological distress and for the purpose of analysis the GHQ score was divided into four groups based on the distribution of scores among all responders as none (0), low (1), medium (2-4) and high (5-12) levels of psychological distress. The GHQ is a validated instrument for use in community surveys and was designed to cover four identifiable elements of distress: depression, anxiety, social impairment and hypochondriasis.

- Maladaptive response to illness: this was assessed using thirty yes/no questions on the illness behaviour questionnaire (IBQ). ${ }^{13}$ These questions were grouped into seven sub-scales. The seven sub scales describe an altered response to illness: ${ }^{14}$

1. General hypochondriasis: a general factor marked by phobic concern about one's state of health.

2. Disease conviction: characterised by affirmation that physical disease exists, symptom preoccupation, and rejection of the doctor's reassurance.

3. Psychological vs. somatic perception of illness: a high score indicates that the person feels somehow responsible for the illness, and perceives the need of psychiatric rather than medical treatment. A low score indicates a rejection of such attitudes and a tendency to somatise concerns.

4. Affective inhibition: a high score indicates difficulty in expressing personal feelings, especially negative ones, to others.
5. Affective disturbance: characterised by feelings of anxiety and /or sadness.

6. Denial: a high score indicates a tendency to deny life stresses, and to attribute all problems to the effects of illness.

7. Irritability: assesses the presence of angry feelings, and interpersonal friction.

- Other comorbidities: sleep disturbance score. ${ }^{15}$ The total sleep score was calculated as a sum of four responses measured on a scale from 0 to 5 (range $0-20$ ).

\section{Statistical analysis}

Continuous variables were categorised using percentiles of the overall distribution. The magnitude of association between deprivation and oro-facial pain was described by the odds ratio (OR) using logistic regression analysis. Variables, which could potentially explain the relationship between oro-facial pain and deprivation, were, as potential confounding factors, entered into the logistic regression model. Statistical analyses were performed using SPSS for Windows (Version 9).

\section{RESULTS}

Of the 2,504 responders a total of 646 people reported some form of oro-facial pain giving a prevalence of $26 \%$. Table 1 shows the prevalence of oro-facial pain by deprivation. While the prevalence of oro-facial pain varied between 22.1 - 26.5\% in quintiles 1 - 4 of deprivation, those in the most deprived quintile had a prevalence of $34.4 \%$. In comparison with the most affluent population group, those in the most deprived had significantly increased odds of reporting oro-facial pain; OR 1.50 (95\% CI: $1.09-2.07)$.

Table 1 Prevalence of oro-facial pain by deprivation score.

\begin{tabular}{|c|c|c|c|c|}
\hline \multirow{2}{*}{\multicolumn{2}{|c|}{ Townsend deprivation score * }} & \multicolumn{2}{|c|}{ Oro-facial pain } & \multirow{2}{*}{$\begin{array}{l}\text { Odds Ratio } \\
95 \% \mathrm{Cl}\end{array}$} \\
\hline & & Yes & No & \\
\hline 1. Affluent & -7.55 to -3.11 & $357(25.8 \%)$ & $1,026(74.2 \%)$ & 1 \\
\hline 2. & -3.10 to -1.56 & $102(22.1 \%)$ & $360(77.9 \%)$ & $0.81(0.63-1.05)$ \\
\hline 3. & -1.55 to 0.38 & 79 (25.6\%) & $230(74.4 \%)$ & $0.99(0.74-1.31)$ \\
\hline 4. & 0.39 to 3.13 & $41(26.5 \%)$ & $114(73.5 \%)$ & $1.03(0.71-1.51)$ \\
\hline 5. Deprived & 3.14 to 11.80 & $67(34.4 \%)$ & $128(65.5 \%)$ & $1.50(1.09-2.07)$ \\
\hline
\end{tabular}

*Categories were determined using quintiles of the overall distribution for England and Wales

Those living in areas with the highest levels of deprivation were significantly younger, less likely to have annual dental check-ups and showed a more exaggerated response to their illness (Tables 2a and 2b). Specific aspects of illness behaviour related to attributing all their problems to illness, inability to express their feeling to others and showing increased anxiety and irritability (IBQ scales $4-7$; Table 2 b). They were also more likely to be female, report facial trauma, high levels of sleep disturbance, high levels of psychological distress and greater levels of hypochondriasis, although these differences were not statistically significant (Tables 2a and 2 b).

We examined whether any of these potential confounding factors could explain the increased prevalence of oro-facial pain in those living in areas with the highest levels of deprivation. Each of the potential confounders (listed above) was entered into a logistic regression model together with deprivation score. None of these factors resulted in a more than $10 \%$ change to the increased odds ratio with the adjusted odds ratios ranging from 1.39 to 1.64 (Table 3). Even when all these potential factors were entered into a model, the highest levels of deprivation were still associated with an increased odds of orofacial pain; OR 1.36 (95\% CI: 0.81 - 2.30). Therefore these potential confounding factors could not explain the observed relationship between oro-facial pain and deprivation. 
RESEARCH

Table 2a Relationship between deprivation and potential confounding factors.

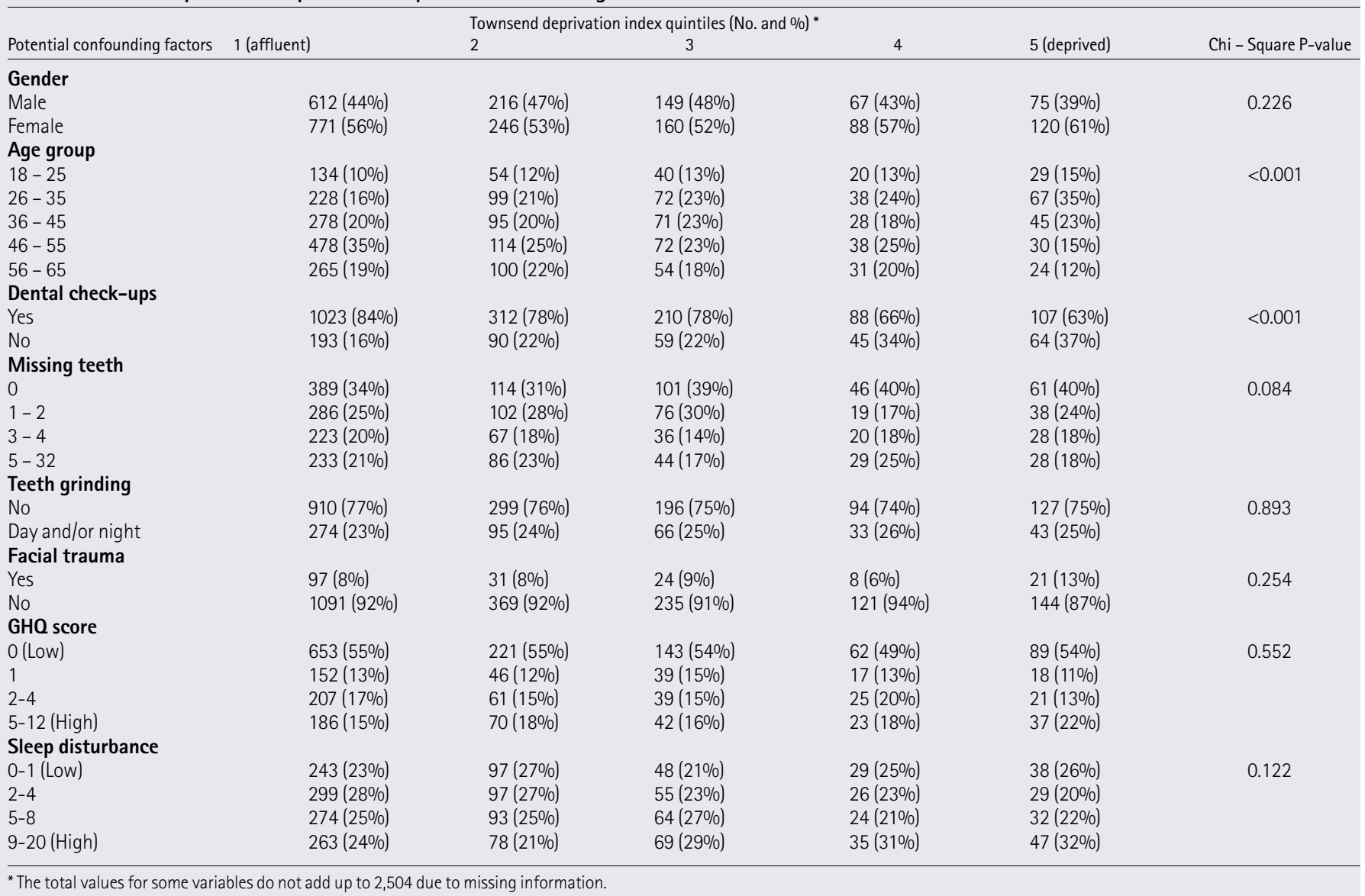

Table $2 \mathrm{~b}$ Relationship between deprivation and potential confounding factors.

\begin{tabular}{|c|c|c|c|c|c|c|}
\hline \multirow[b]{2}{*}{ Potential confounding factors } & \multicolumn{5}{|c|}{ Townsend deprivation index quintiles (No. and \%)* } & \multirow[b]{2}{*}{ Chi - Square P-value } \\
\hline & 1 (affluent) & 2 & 3 & 4 & 5 (deprived) & \\
\hline \multicolumn{7}{|c|}{ IBO score } \\
\hline \multicolumn{7}{|c|}{ Scale 1 (General hypochondriasis) } \\
\hline 0 & $577(51 \%)$ & $190(50 \%)$ & $143(57 \%)$ & $67(55 \%)$ & $84(53 \%)$ & 0.083 \\
\hline 1 & $292(26 \%)$ & $99(26 \%)$ & $55(22 \%)$ & $20(16 \%)$ & $28(18 \%)$ & \\
\hline $2-8$ & $271(23 \%)$ & $93(24 \%)$ & $52(21 \%)$ & $35(29 \%)$ & $46(29 \%)$ & \\
\hline \multicolumn{7}{|c|}{ Scale 2 (Disease conviction) } \\
\hline 0 & $240(22 \%)$ & $86(24 \%)$ & $63(26 \%)$ & $36(30 \%)$ & $36(23 \%)$ & 0.201 \\
\hline 1 & $414(38 \%)$ & $128(36 \%)$ & $93(38 \%)$ & $34(28 \%)$ & $47(31 \%)$ & \\
\hline $2-6$ & $433(40 \%)$ & $145(40 \%)$ & $86(36 \%)$ & $50(42 \%)$ & $70(46 \%)$ & \\
\hline \multicolumn{7}{|c|}{ Scale 3 (Perception of illness) } \\
\hline $0-1$ & $277(24 \%)$ & $106(27 \%)$ & $65(26 \%)$ & $36(29 \%)$ & $42(25 \%)$ & 0.584 \\
\hline $2-4$ & $896(76 \%)$ & $288(73 \%)$ & $190(74 \%)$ & $90(71 \%)$ & $125(75 \%)$ & \\
\hline \multicolumn{7}{|c|}{ Scale 4 (Affective inhibition) } \\
\hline 0 & $515(44 \%)$ & $160(41 \%)$ & $100(38 \%)$ & $40(32 \%)$ & $51(31 \%)$ & 0.002 \\
\hline 1 & $406(34 \%)$ & $132(33 \%)$ & $77(30 \%)$ & $50(39 \%)$ & $69(42 \%)$ & \\
\hline 2 & $264(22 \%)$ & $102(26 \%)$ & $84(32 \%)$ & $37(29 \%)$ & $46(27 \%)$ & \\
\hline 0 & $637(54 \%)$ & $200(50 \%)$ & $136(52 \%)$ & $64(51 \%)$ & $67(41 \%)$ & 0.040 \\
\hline 1 & $272(23 \%)$ & $91(23 \%)$ & $53(20 \%)$ & $30(24 \%)$ & $45(28 \%)$ & \\
\hline 2 & $181(15 \%)$ & $68(17 \%)$ & $41(16 \%)$ & $17(13 \%)$ & $22(13 \%)$ & \\
\hline 3 & $100(8 \%)$ & $38(10 \%)$ & $32(12 \%)$ & $15(12 \%)$ & $28(17 \%)$ & \\
\hline \multicolumn{7}{|l|}{ Scale 6 (Denial) } \\
\hline $0-1$ & $296(25 \%)$ & $98(25 \%)$ & $78(29 \%)$ & $47(36 \%)$ & $76(45 \%)$ & $<0.001$ \\
\hline 2 & $902(75 \%)$ & $302(75 \%)$ & $188(71 \%)$ & $83(64 \%)$ & $91(55 \%)$ & \\
\hline \multicolumn{7}{|l|}{ Scale 7 (Irritability) } \\
\hline 0 & $596(52 \%)$ & $192(49 \%)$ & $133(52 \%)$ & $56(45 \%)$ & $61(38 \%)$ & 0.036 \\
\hline 1 & $318(27 \%)$ & $110(28 \%)$ & $61(23 \%)$ & $33(27 \%)$ & $52(32 \%)$ & \\
\hline $2-3$ & $243(21 \%)$ & $90(23 \%)$ & $64(25 \%)$ & $35(28 \%)$ & $49(30 \%)$ & \\
\hline
\end{tabular}

*The total values for some variables do not add up to 2,504 due to missing information.

\section{DISCUSSION}

This study has shown a significant relationship between orofacial pain and deprivation, with the likelihood of persons in the most deprived areas reporting oro-facial pain 1.5 times those in the most affluent areas. The study achieved a good participation rate, and the participants may be considered to be representative of the general population, as over 95\% of the United Kingdom population is registered with a general medical practitioner. 
Table 3 Odds ratios with $95 \% \mathrm{Cl}$ for oro-facial pain in deprivation categories 1-5 after adjustment for the variables shown.

\begin{tabular}{|c|c|c|c|c|c|}
\hline \multirow[b]{2}{*}{ Adjustment } & \multicolumn{5}{|c|}{ Townsend deprivation index quintiles (Odds Ratio and 95\% $\mathrm{Cl}$ ) } \\
\hline & 1 (affluent) & 2 & 3 & 4 & 5 (deprived) \\
\hline \multirow[t]{2}{*}{ Crude } & 1 & 0.81 & 0.99 & 1.03 & 1.50 \\
\hline & & $0.63-1.05$ & $0.74-1.31$ & $0.71-1.51$ & $1.09-2.07$ \\
\hline \multirow[t]{2}{*}{ Age group } & 1 & 0.81 & 0.97 & 1.02 & 1.44 \\
\hline & & $0.63-1.04$ & $0.73-1.29$ & $0.70-1.49$ & $1.04-1.99$ \\
\hline \multirow[t]{2}{*}{ Gender } & 1 & 0.82 & 1.01 & 1.03 & 1.47 \\
\hline & & $0.64-1.06$ & $0.76-1.34$ & $0.70-1.50$ & $1.07-2.03$ \\
\hline \multirow[t]{2}{*}{ Dental check-ups } & 1 & 0.82 & 1.04 & 1.03 & 1.57 \\
\hline & & $0.63-1.07$ & $0.77-1.40$ & $0.69-1.54$ & $1.12-2.21$ \\
\hline \multirow[t]{2}{*}{ Missing teeth } & 1 & 0.83 & 1.01 & 1.18 & 1.57 \\
\hline & & $0.63-1.09$ & $0.74-1.38$ & $0.77-1.80$ & $1.10-2.23$ \\
\hline \multirow[t]{2}{*}{ Day and/or night grinding } & 1 & 0.78 & 1.00 & 1.04 & 1.56 \\
\hline & & $0.59-1.02$ & $0.73-1.36$ & $0.68-1.57$ & $1.10-2.20$ \\
\hline \multirow[t]{2}{*}{ Facial trauma } & 1 & 0.81 & 1.01 & 1.03 & 1.59 \\
\hline & & $0.62-1.06$ & $0.74-1.38$ & $0.68-1.57$ & $1.13-2.25$ \\
\hline \multirow[t]{2}{*}{ GHQ score } & 1 & 0.81 & 1.04 & 0.96 & 1.55 \\
\hline & & $0.61-1.06$ & $0.76-1.42$ & $0.62-1.47$ & $1.08-2.22$ \\
\hline \multirow[t]{2}{*}{ IBO 1 (General Hypochondriasis) } & 1 & 0.84 & 1.06 & 1.02 & 1.62 \\
\hline & & $0.64-1.10$ & $0.77-1.45$ & $0.66-1.57$ & $1.14-2.32$ \\
\hline \multirow[t]{2}{*}{ IBO 2 (Disease Conviction) } & 1 & 0.80 & 1.04 & 1.12 & 1.55 \\
\hline & & $0.60-1.07$ & $0.75-1.44$ & $0.73-1.72$ & $1.07-2.23$ \\
\hline \multirow[t]{2}{*}{ IBO 3 (Perception Of IIIness) } & 1 & 0.81 & 1.02 & 1.02 & 1.51 \\
\hline & & $0.61-1.06$ & $0.75-1.39$ & $0.67-1.55$ & $1.07-2.14$ \\
\hline \multirow[t]{2}{*}{ IBO 4 (Affective Inhibition) } & 1 & 0.85 & 1.04 & 0.96 & 1.51 \\
\hline & & $0.65-1.11$ & $0.77-1.42$ & $0.63-1.46$ & $1.07-2.13$ \\
\hline \multirow[t]{2}{*}{ IBO 5 (Affective Disturbance) } & 1 & 0.78 & 1.02 & 1.06 & 1.42 \\
\hline & & $0.60-1.03$ & $0.75-1.39$ & $0.69-1.61$ & $0.99-2.02$ \\
\hline \multirow[t]{2}{*}{ IBO 6 (Denial) } & 1 & 0.84 & 1.02 & 0.99 & 1.39 \\
\hline & & $0.64-1.10$ & $0.76-1.39$ & $0.65-1.49$ & $0.98-1.97$ \\
\hline \multirow[t]{2}{*}{ IBO 7 (Irritability) } & 1 & 0.85 & 1.07 & 1.05 & 1.55 \\
\hline & & $0.65-1.11$ & $0.79-1.45$ & $0.69-1.60$ & $1.09-2.20$ \\
\hline \multirow[t]{2}{*}{ Sleep disturbance score } & 1 & 0.81 & 0.88 & 1.05 & 1.64 \\
\hline & & $0.61-1.08$ & $0.63-1.23$ & $0.67-1.64$ & $1.13-2.40$ \\
\hline \multirow[t]{2}{*}{ Adjusted for all factors } & 1 & 0.79 & 0.82 & 1.14 & 1.36 \\
\hline & & $0.55-1.15$ & $0.53-1.26$ & $0.63-2.00$ & $0.81-2.30$ \\
\hline
\end{tabular}

There are some methodological aspects, which warrant consideration. Firstly, our study was conducted in 1997-1998 but used 1991 census data to measure deprivation, as this was the only data available to us. However, there have been little changes in relative socio-economic status of the study population during the past decade. Secondly, there are methodological issues in measuring deprivation. Morris and Carstairs ${ }^{16}$ examined the correlation of several deprivation indices with various health measures using data for postcode sectors in Scotland. The Townsend index was one of two indices found to explain most variation in health measures and to adhere closely to the concept of material disadvantage. Finally, the current study is cross-sectional, and therefore some factors studied may not be risk factors for oro-facial pain but a consequence of symptoms.

Other cross-sectional population-based studies have found that pain, including oro-facial pain, is more common in those of lower socio-economic status. ${ }^{3,4,6}$ However, some pain studies have failed to find an association. ${ }^{17,18,19,20,21}$ These studies only used one variable, for example social class or income, to meas- ure deprivation. The Townsend index is a more valid measure of material disadvantage, ${ }^{16}$ as it is a composite score based on four key variables.

In conclusion, this cross-sectional community-based survey adds to the knowledge on relationship between deprivation and pain, showing a positive association with oro-facial pain. The mechanism however, remains elusive. Understanding the mechanism is crucial to facilitate our understanding of how to reduce the burden of common disabling regional pain syndromes in certain population groups.

The authors are grateful to staff and patients of Lawton House Surgery for their help with the study. V. R. Aggarwal was supported by a Wellcome Trust entry-level fellowship and currently holds a Wellcome Trust clinical epidemiology research fellowship

1. Carstairs V. Deprivation indices: their interpretation and use in relation to health. $J$ Epidemiol Comm Health 1995; 49 (Suppl 2): S3-S8.

2. Morgan C L, Ahmed Z, Kerr M P. Social deprivation and prevalence of epilepsy and associated health usage J Neurol Neurosurg Psychiatry 2000 : 69:13-17.

3. Andersson H I, Ejlertsson $\mathrm{G}$, Leden I, Rosenberg C. Chronic pain in a geographically defined general population: studies of differences in age, gender, social class and pain ocalization. Clin J Pain 1993: 9: 174-182. 
4. Papageorgiou A C, Macfarlane G J, Thomas E, Croft PR, Jayson M I V, Silman A J. Psychosocial factors in the workplace - do they predict new episodes of low back pain? Spine 1997; 10: 1137-1142.

5. Locker D. The burden of oral disorders in a population of older adults. Community Dent Health 1992; 9: 109-124.

6. Vargas C M, Macek M D, Marcus S E. Sociodemographic correlates of tooth pain among adults: United States, 1989. Pain 2000; 85: 87-92.

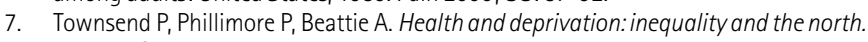
London: Croom Helm; 1988.

8. Prendergast M J, Beal J F, Williams S A. The relationship between deprivation, ethnicity and dental health in 5 year old children in Leeds, UK. Community Dent Health 1997; 14: 18-21.

9. Provart S J, Carmichael C L. The relationship between caries, fluoridation and material deprivation in five-year-old children in County Durham. Community Dent Health $1995 ; 12 ; 200-203$.

10. Provart S J, Carmichael C L. The use of an index of material deprivation to identify groups of children at risk to dental caries in County Durham. Community Dent Health. $1995 ; 12 ; 138-142$.

11. The 1991 Census, Crown Copyright, ESRC

12. Goldberg D. Manual of the general health questionnaire. Windsor, England: NFER Publishing, 1978.
13. Pilowsky I, Spence N D. Manual for the illness behaviour questionnaire (IBQ). 2nd ed. Adelaide, Australia: University of Adelaide, 1983.

14. McDowell I, Newell C. Measuring health: a guide to rating scales and questionnaires. Oxford University Press: Oxford; 2nd Edition, 1996.

15. Jenkins C D, Stanton B A, Niemcryk S J, Rose R M. A scale for the assessment of sleep problems in clinical research. J Clin Epidemiol 1988; 41:313-321.

16. Morris $R$, Carstairs V. Which deprivation? A comparison of selected deprivation indexes J Public Health Med 1991; 13:318-326.

17. Goulet J P, Lavigne G J, Lund J P. Jaw pain prevalence among French-speaking Canadians in Quebec and related symptoms of temporomandibular disorders. J Dent Res 1995; 74: 1738-1744.

18. Lipton J A, Ship J A, Larach Robinson D. Estimated prevalence and distribution of reported oro-facial pain in the United States. J Am Dent Assoc 1993; 124: 115121.

19. Locker D, Leake J L, Hamilton M, Hicks T, Lee J, Main P A. The oral health status of older adults in four Ontario communities. J Can Dent Assoc 1991; 57: 727-732.

20. Tickle $M$, Craven $R$, Worthington H V. A comparison of the subjective oral health status of older adults from deprived and affluent communities. Community Dent Oral Epidemiol 1997; 25: 217-222.

21. Von Korff M, Dworkin S F, Le Resche L, Kruger A. An epidemiologic comparison of pain complaints. Pain 1988; 32: 173-183.

\section{A change in recording tooth notation}

The BDJ has traditionally adopted the Palmer tooth notation as the first choice for recording individual teeth in papers and articles. This system, very familiar to dentists in the UK, is reproduced below for both adult and deciduous teeth.

\begin{tabular}{|c|c|}
\hline 87654321 12345678 & EDCBA | ABCDE \\
\hline \begin{tabular}{l|l}
87654321 & 12345678
\end{tabular} & $\overline{\mathrm{EDCBA}}$ \\
\hline
\end{tabular}

We recently changed the actual way the Palmer system is written because of difficulties converting the familiar grid format to our website. Instead the position on the grid is now written using the shorthand UR for upper right, UL for upper left, LL for lower left and LR for lower right.

Thus 7 becomes UR7 and $\longdiv { 5 }$ is written as LL5. Groups of teeth will be recorded as best we can, so for example 54 will become UR5 and UR4, while 2345 will be written as UL2 to UL5.

Obviously the same will apply to deciduous teeth, for example E I will be written as URE.

The FDI notation will still be written in brackets after the Palmer notation, using the familiar FDI notation as described below:

\begin{tabular}{llllll|llllll}
18171615141312 & 11 & 21 & 22 & 23 & 24 & 252627 & 28
\end{tabular} for adult teeth

and

\begin{tabular}{l|l|l}
5554535251 & 6162636465 \\
\hline 8584838281 & 7172737475
\end{tabular} for deciduous teeth

Thus using both systems, 7] will be written as UR7 (17) and $[5$ will become LL5 (35). 